\title{
Digital twin requirements in the context of Industry 4.0
}

\author{
Luiz Fernando C. S. Durão ${ }^{1}$, Sebastian $\mathrm{Haag}^{2}$, Reiner Anderl ${ }^{2}$, Klaus Schützer ${ }^{1}$, \\ Eduardo Zancul ${ }^{1 *}$ \\ ${ }^{1}$ University of São Paulo, Brazil \\ luiz.durao@usp.br \\ ezancul@usp.br \\ schuetzer@scpm.unimep.br \\ ${ }^{2}$ Technische Universität Darmstadt, Germany \\ haag@dik.tu-darmstadt.de \\ anderl@dik.tu-darmstadt.de
}

* to whom correspondence should be addressed

\begin{abstract}
Digital Twin (DT) is being considered a significant enabler for Industry 4.0 initiatives. Within Industry 4.0 , the amount of digital product information generated and collected over the entire lifecycle has been growing. Current information and communication technologies, including data storage, data processing, and wireless data transmission, may be leveraged to digitally mirror the lifecycle of a corresponding physical product with increasing level of detail. A DT creates a link between physical products and their virtual models with more comprehensive data and accumulation of knowledge. Therefore, a DT may be applied to enhance simulation, traceability and to support the offering of valueadded services along the lifecycle. However, the definition of a DT and its requirements are not yet fully established. The characteristics a DT model should possess to be widely used in manufacturing remains an open question in the literature. The concept is still broad and dependent on the lifecycle stage and industry sector of application. Therefore, the objective of this paper is to propose an initial synthesis of DT requirements based on a literature review and industry interviews. The literature review focuses on the content analysis of papers published from 2010 to 2018 and indexed in the ISI Web of Science database. The interviews were conducted with industry representatives in Brazil. The results show that DT requirements are related to real-time data, integration, and fidelity. Besides, it shows that industry requirements are close to literature and the actual implementation of DT is the future of research in this field.
\end{abstract}

Keywords: Digital Twin; Industry 4.0; Product Lifecycle Management. 


\section{Introduction}

Industrial revolutions alter product manufacturing processes as well as how consumers interact with production, allowing sophistication of the demand for different consumer goods [1]. Before the first Industrial Revolution, the products were manufactured in a handmade way, according to the individual demands of each consumer and taking the time of the artisan to be manufactured. From the first Industrial Revolution, production processes began to be mechanized (first revolution), to be treated as massive processes (second revolution), and to be automatized (third revolution), standardizing the products in exchange for an increase in the efficiency of the production line [2]. The fourth Industrial Revolution - or Industry 4.0 - comes with the proposal to unite the advantages of large-scale production with the individualization. Hence, virtual product models, which are frequently referred to as Digital Twins, are used as fuel to shortening time to market and to create further benefits along the entire lifecycle [3].

The convergence between physical and virtual spaces has gained wide attention recently [4]. Digital Twin (DT) is defined as a very realistic model of the current state of the process and their own behavior in interaction with their environment in the real world [5]. It is used not only for representation purposes but also for predicting the product behavior [3]. Besides, Digital Twin's ability to link enormous amounts of data to fast simulation makes it possible to perform real-time optimization of products and production processes [6].

However, the definition of a DT and its requirements are not yet fully established and lack of conceptual basis [3]. The characteristics a DT model should possess to be widely used in industry remains an open question in the literature.

Therefore, this paper aims to narrow this research gap by proposing an initial synthesis of Digital Twin requirements. The paper seeks to answer the following research question (RQ1): what are main requirements for developing a Digital Twin? Besides, it aims to investigate (RQ2): what industry understands as Digital Twin?

A systematic literature review, merging bibliometrics and content analysis [7], was applied to identify the main requirements listed in literature for Digital Twins. The literature review focused on a content analysis of articles published from 2010 to 2018 in the ISI Web of Science database. After literature review, a set of interviews with industry representatives were conducted in Brazil.

The paper is structured in five sections. After the introduction of the research topic in Section 1, Section 2 provides the research approach developed in the paper. In Section 3, the requirements brought by literature to the Digital Twin concept are presented. Section 4 presents industry requirements for Digital Twin. Finally, the conclusion and an outlook on further research needs are discussed in Section 5.

\section{Methodology}

To acquire a broad knowledge about Digital Twins, this research firstly took into consideration the possible ways a literature review can be developed [8]. The research design combines quantitative and qualitative strategies. It merges bibliometrics and 
content analysis, to study a research topic, as they are complementary methods [7]. Mainly, this kind of methodology is used not only to probe the existing literature and to identify relevant patterns, words, and authors of the particular field of research, but also to investigate the evolution of the publications stratified by journals [9].

Decisions on which research method to apply are mainly taken based on the results from the databases, particularly the sample size to be reviewed [7]. The bibliometric approach is particularly useful for large sample sizes since it focuses on metrics based on the number of publications and the metadata. Content analysis, on the other hand, focuses on in-depth review of the sample but allows analytical flexibility $[9,10]$.

The second part of the research methodology consisted of industry interviews target at discovering the implications of Digital Twin in real cases and the requirements given by manufacturing companies to the concept deployment.

\subsection{Sampling}

For this paper, an initial sample was elaborated using the ISI Web of Science, aiming to cross-check their results and enhance some documents to be studied. The article search was performed in January and February 2018. The following search string was used, and no restrictions were considered: "Digital Twin" and ("Industry 4.0" or "Requirement*"), and "Digital Twin". This first search resulted in 52 entries in ISI Web of Science.

The first exclusion criteria were based on the abstracts and title reading. All these papers had their abstracts read for identifying those that did not fit within the scope of the study, excluding them from the final list, resulting in 20 papers. It was not possible to have access to the full paper of one article, resulting in 19 articles. All the papers from the final list were read to identify the Digital Twin requirements contained in the papers to be used in the content analysis.

All the 52 papers had been published from 2010 to 2017, in 47 different journals and conferences, and $85 \%$ of the papers had their publication concentrated in the last three years. Among the conferences and journals, the "IFAC papersonline", the "IEE access", and the "Manufacturing Systems 4.0" have the most papers in the subject (3), and there are 198 authors and the authors that have the most articles possess two publications.

\subsection{Industry selection and questions}

Interviews with six industry representatives from Brazil and Germany have shown that there is growing interest in Digital Twin technologies. However, there are many reservations regarding feasibility, and application. These issues will be discussed in more detail in Section 4 to derive the industry-specific requirements for Digital Twin. The companies answered five different questions regarding Digital Twin:

1. Have you heard about Digital Twin concept?

2. What do you understand by Digital Twin?

3. Do you use Digital Twins in your processes?

4. What are, in your point of view, the main requirements for the implementation of Digital Twins in your processes?

5. What is your future plan concerning the use of Digital Twin? 
Interviews were conducted by telephone with 7 representatives from 6 different companies: two automotive OEM, three manufacturing technology providers, and one ERP software provider.

After answering the questions, the requirements showed in literature were compared with the requirements and concerns defined by the industry.

\section{Literature requirements}

In this section, it is presented a discussion of three different topics, Industry 4.0 (3.1), and Digital Twin (3.2). At the end of this section, as a result of the literature review, Table 1 is presented summarizing the requirements brought by literature to the Digital Twin concept.

\subsection{Industry 4.0}

Industry 4.0 is a new approach to the manufacturing chain that aims to integrate manufacturing systems creating a self-controlled and intelligent environment. A controlled environment can promote information about the lifecycle and close the product information loop [11].

Connected environments, promoted by Industry 4.0, consider the production of more individualized products without interrupting the production line, since consumer orders are directly connected to production planning via the network $[2,12]$.

Factories are rapidly becoming adaptable while remaining economically productive. This situation allows the decentralization of production - through autonomous tasks based on Cyber Physical Production Systems [13-15]. Intelligent factories will be connected in a collaborative network sharing information relevant to a database and thus creating a dynamic environment with the use of technologies such as Artificial Intelligence, Internet of Things among others [2].

The implementation of intelligent factories is possible considering the evolution of manufacturing and information technologies, being able to receive different information from different sources and produce items that are more complex in a reduced time and in different locations. This change in production technologies requires a new representation of manufacturing processes and product models. This representation would be reached by a Digital Twin.

\subsection{Digital Twin}

Digital Twin is a multi-physical, multi-scale, and probabilistic simulation model of a complex product. It uses updated sensors and physical models to mirror physical life in the digital world and vice versa $[16,17]$. Technologies for mapping Digital Twins are being developed for approximately 20 years [17].

However, it was the digital manufacturing and the Cyber Physical Production Systems (CPPS) that allowed the enrichment of the Digital Twin models through production and operation data [3]. More specifically, the development of sensing 
technologies and information technologies allowed the integration of digital models with the real-time information of the physical product [3].

Information such as sensor readings, alarms, assembly, disassembly, shipping event, and other information related to the entire product lifecycle needed to be exchanged between products and systems [18]. The role of the PLM system is collecting and managing data of product definitions, processes, resources and decisions across the whole product lifecycle supporting changes and enabling traceability of these changes through a Product Model [19].

The product model that supports the data interfacing (and then systems interoperability) should describe, with the same semantic, various data. In low trust level, the product model is used to manage the product information separately in different databases [20]. Therefore, managing the interaction between the physical and digital world starts from the product model. The DT must manage the interaction of the product model and the physical world and its requirements must reflect that.

The different understandings of the term Digital Twin can be observed in cases in the industry. Some manufacturers focus on building a link between the virtual product and the physical product, increasing manufacturing flexibility. Other manufacturers are looking to use Digital Twin to improve product design; and others are using DT to map the product throughout its life cycle improving quality in manufacturing [3]. The challenge lies in the fact that there are few possibilities for the synchronization between the physical world and the digital world making it difficult to close the information loop.

To be considered a Digital Twin, the model must have some specific characteristics such as: scalability (ability to analyze different scales of information); interoperability (ability to convert, match and establish equivalence between representation models); expansibility (ability to integrate models); and fidelity (ability to conform to the physical model) [3].

Considering the comprehensive study of the "Digital Twin" definitions shown previously, the numbers of requirements to describe "Digital Twin" are numerous. The different characteristics are summarized in Table 1, which demonstrates the relations between the parameters (lines) and the citation (columns) and total citation (final column Total). 
Table 1. Literature requirements for Digital Twin

\begin{tabular}{|c|c|c|c|c|c|c|c|c|c|c|c|c|c|c|c|c|c|}
\hline Requirement & $\bar{\beth}$ & $\Xi$ & ㄱ & $\sqrt[\widetilde{d}]{ }$ & $\underset{d}{J}$ & $\sqrt[n]{n}$ & 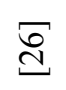 & $\sqrt{n}$ & $\bar{n}$ & $\stackrel{\sigma}{\Xi}$ & $\Xi$ & $\widehat{ָ}$ & $\stackrel{\infty}{\stackrel{\infty}{d}}$ & ปे & 욜 & $\sigma$ & $\underset{\tilde{\theta}}{\tilde{\sigma}}$ \\
\hline Real-time data & & & 1 & & & 1 & 1 & & & & & & 1 & & 1 & 1 & 7 \\
\hline Integration & & & 1 & 1 & & 1 & & & & & & & & 1 & 1 & 1 & 6 \\
\hline Fidelity & & & & 1 & 1 & & 1 & & 1 & & 1 & & 1 & & & & 6 \\
\hline Interaction & 1 & & & & & & & & & 1 & 1 & & & & & & 3 \\
\hline Communication & 1 & & & & & & & & & & 1 & & & & & & 2 \\
\hline Convergence & & & & & & & & & & 1 & 1 & & & & & & 2 \\
\hline $\begin{array}{l}\text { Automatically } \\
\text { updated }\end{array}$ & & 1 & & & & & & & & & & & & & & & 1 \\
\hline Autonomy & & & & & & & & 1 & & & & & & & & & 1 \\
\hline Connectivity & & & & & & & & 1 & & & & & & & & & 1 \\
\hline Data acquisition & & & & & & & & & & & & & 1 & & & & 1 \\
\hline Data capture & & & & & & & & & & & & & & 1 & & & 1 \\
\hline Data quality & & & & & & & 1 & & & & & & & & & & 1 \\
\hline Data security & & & & & & & & & & & & 1 & & & & & 1 \\
\hline $\begin{array}{l}\text { Data } \\
\text { warehousing }\end{array}$ & & & & & & & & & & & & & 1 & & & & 1 \\
\hline Efficiency & & & & & 1 & & & & & & & & & & & & 1 \\
\hline Expansibility & & & & & & & & & 1 & & & & & & & & 1 \\
\hline $\begin{array}{l}\text { Globally } \\
\text { available in real- } \\
\text { time }\end{array}$ & & 1 & & & & & & & & & & & & & & & 1 \\
\hline $\begin{array}{l}\text { Independently } \\
\text { expanded }\end{array}$ & & 1 & & & & & & & & & & & & & & & 1 \\
\hline Interoperability & & & & & & & & & 1 & & & & & & & & 1 \\
\hline Modularity & & & & & & & & 1 & & & & & & & & & 1 \\
\hline Process planning & & & & & & & & & & & & & & 1 & & & 1 \\
\hline $\begin{array}{l}\text { Real-time } \\
\text { location }\end{array}$ & & & & & & & & & & & & 1 & & & & & 1 \\
\hline Scalability & & & & & & & & & 1 & & & & & & & & 1 \\
\hline Scalable & 1 & & & & & & & & & & & & & & & & 1 \\
\hline $\begin{array}{l}\text { Stable data } \\
\text { acquisition }\end{array}$ & & & & & & & & & & & & 1 & & & & & 1 \\
\hline Stable operation & & & & & & & & & & & & 1 & & & & & 1 \\
\hline
\end{tabular}


The data from Table 1 enables us to state that the most frequent requirements of Digital Twins are real-time data, integration, and fidelity. These are crucial requirements for connecting the Product Model and the real conditions of the product.

As revealed by Table 1, real-time data was mentioned by 6 among the researched sample of 19 articles being the most cited parameter for Digital Twin requirements. For instance, in [6], real-time data is used for the optimization of products and production processes. The importance of this requirement is also shown by [22], that concludes that, real-time data is important for knowing the status of the product. In [25], real-time data requirements focus on the management and optimization of processes through monitoring and data analytics.

Data integration is the second most cited parameters for Digital Twin requirements. Integration is the most important value creation in the Digital Twin world [28]. A realworld object is represented by different subgraphs of nodes and edges. The integration of the different nodes is essential for creating valuable data [22]. In [23], integration is shown as the way to create the visual abstract that represents the anatomy of Digital Twin.

Fidelity, the third most cited parameter, is essential to mirror physical entities [4]. A high fidelity simulation model has several potential uses in organizations. It allows an operator to train on virtual machine, provide a basis for increasing the self-awareness of the machine [26]. The abstract representation of the Digital Twin allows the description of different operations in the real world. It is the fidelity of the model that provides the closeness to the physical product [3].

With the literature requirements defined, it is possible to collect industry requirements.

\section{Industry requirements}

In this section it is presented the main results from interviews conducted at industry partners aiming at understanding:

a) The current use of digital twin concept;

b) The vision of the industry about this topic; and

c) The requirements imposed by industry for the development of digital twins.

From the six companies that were interviewed, all were familiar with the Digital Twin concept and claimed to use this model on processes. The interviewed companies demonstrated to understand this component as a digital representation of the physical world and a physical representation of the digital world. It is seen as composed by two different visions a real one, and a utopic one. The utopic is described as the intersection between the digital and the physical. The real one is described as the use of DT as a simulation model for the physical world, without instant connection of data.

One company claimed to use DT model in large scale, simulating the manufacturing lines before the actual implementation of the factory. The system of this company is then alimented with real data. Other companies claimed to use DT concept as part of their business model, selling solutions that englobe DT. 
For the future, the companies intend to implement integration platforms that collect physical data to create an abstraction model which mirrors the physical world with high fidelity allowing real-time control of the manufacturing lines. Each company has a different strategy to achieve that, such as startups acquisitions and in-house development of technology.

Therefore, it is possible to conclude that however industry is well familiar with Digital Twin concept and many of them claimed to already use DT, most of them only use DT as simulation model. The main obstacles to the implementation of DT are a robust integration of data to allow a representation with high fidelity and real-time control of the line. The requirements demanded by industry are the same ones required in literature.

\section{Conclusions and future work}

This paper set out to answer the RQs: (RQ1) what are main criteria for developing a Digital Twin? Besides, it aims to investigate (RQ2) what industry understands as Digital Twin?

For answering the RQ1, this paper provides a rich description and analysis of the Digital Twin requirements in literature. This article contributes to the literature by surveying DT requirements. A total of 19 articles were analyzed, coming from the ISI Web of Science databases.

An analysis of the most frequent related topics on Digital Twin reveals that real-time data, integration, and fidelity are the DT requirements mostly dealt with and valued by the literature.

For the industry, DT is seen as a combination of an academic vision of coexistence of digital and physical world and a real vision of simulation models to improve and implement physical manufacturing lines. All interviewed companies claimed to understand the Digital Twin concept, however the current state of the practice is anchored on simulation models. They understand the difficulties to integrate digital and physical world and described their future strategy as more concerned about actual implementation of real-time control, not only simulation.

Besides, using the same data to draw an evolution of the topics in recent years Table 2 - it is possible to see that, more recently, topics related to the system independence and implementation are becoming more cited in the literature in the last year. Approaching DT by a combination of implementation and reliability requirements appears to be an academic challenging issue for the upcoming research agenda, showing that the actual implementation is gaining more attention than the DT design requirements. 
Table 2. Parameters evolutions in recent years

\begin{tabular}{|c|c|c|c|c|}
\hline Factors & 2015 & 2016 & 2017 & Total \\
\hline Real-time data & & 1 & 6 & 7 \\
\hline Integration & & 1 & 5 & 6 \\
\hline Fidelity & & & 5 & 5 \\
\hline Interaction & & & 3 & 3 \\
\hline Communication & & & 2 & 2 \\
\hline Convergence & & & 2 & 2 \\
\hline Scalability & & & 1 & 1 \\
\hline Modularity & 1 & & & 1 \\
\hline Data acquisition & & & 1 & 1 \\
\hline Data security & & & 1 & 1 \\
\hline Data capture & & & 1 & 1 \\
\hline Data warehousing & & & 1 & 1 \\
\hline Data quality & & & 1 & 1 \\
\hline Efficiency & & & 1 & 1 \\
\hline Interoperability & & & 1 & 1 \\
\hline Expansibility & & & 1 & 1 \\
\hline Process planning & & & 1 & 1 \\
\hline Stable operation & & & 1 & 1 \\
\hline Real-time location & & & 1 & 1 \\
\hline $\begin{array}{l}\text { Stable data } \\
\text { acquisition }\end{array}$ & & & 1 & 1 \\
\hline Scalable & & & 1 & 1 \\
\hline Connectivity & 1 & & & 1 \\
\hline Autonomy & 1 & & & 1 \\
\hline $\begin{array}{l}\text { Independently } \\
\text { expanded }\end{array}$ & & & 1 & 1 \\
\hline $\begin{array}{l}\text { Automatically } \\
\text { updated }\end{array}$ & & & 1 & 1 \\
\hline $\begin{array}{l}\text { Globally available } \\
\text { in real-time }\end{array}$ & & & 1 & 1 \\
\hline
\end{tabular}

This research has limitation due to the methodological choices, particularly related to the sample analyzed. The database choices, the search strings applied and topic analyzed have possible bias; hence, important articles can be missed in the process. Moreover, interviews were limited in number and to only one country. 
The future of the research into the field is still open. Just recently, new parameters have been discussed as part of DT requirements. Especially the ones related to the actual implementation of DT models in manufacturing industries. Based on current DT requirements definition, future research in the field could explore additional DT requirements related to the actual implementation of DT models in manufacturing industries. Therefore, future work may focus on real DT case simulations - such as in labs and learning factories -, and pilot implementations.

\section{Acknowledgments}

The authors thank the Coordination for the Improvement of Higher Education Personnel (Capes), the Brazilian National Council for Scientific and Technological Development (CNPq), and the German Research Foundation (DFG) for supporting related projects. The authors also thank the companies involved for providing real case applications.

\section{References}

1. Hobsbawn E (1961) The Age of Revolution

2. Kagermann H, Wahlster W, Helbig J (2013) Recommendations for implementing the strategic initiative INDUSTRIE 4.0. Final Rep Ind 40 WG 82

3. Schleich B, Anwer N, Mathieu L, Wartzack S (2017) Shaping the digital twin for design and production engineering. CIRP Ann - Manuf Technol 66:141-144 . doi: 10.1016/j.cirp.2017.04.040

4. Tao F, Zhang M (2017) Digital Twin Shop-Floor: A New Shop-Floor Paradigm Towards Smart Manufacturing. IEEE Access 5:20418-20427 . doi: 10.1109/ACCESS.2017.2756069

5. Rosen R, Von Wichert G, Lo G, Bettenhausen KD (2015) About the importance of autonomy and digital twins for the future of manufacturing. IFAC-PapersOnLine 28:567-572 . doi: 10.1016/j.ifacol.2015.06.141

6. Zhang H, Liu Q, Chen X, et al (2017) A digital twin-based approach for designing and decoupling of hollow glass production line. IEEE Access 1-1 . doi: 10.1109/ACCESS.2017.2766453

7. Carvalho MM, Fleury A, Lopes AP (2013) An overview of the literature on technology roadmapping (TRM): Contributions and trends. Technol Forecast Soc Chang 80:14181437

8. Boote DN, Beile P (2005) Scholars Before Researchers: On the Centrality of the Dissertation Literature Review in Research Preparation. Educ Res 34:3-15 . doi: 10.3102/0013189X034006003

9. Durão LFCS, Grotti MVF, Maceta PRM, et al (2017) A review of the soft side in project management: concept, trends and challenges. GEPROS Gestão da Produção, Operações e Sist 12:157-176 . doi: 10.15675/gepros.v12i2.1644

10. Duriau V., Reger R., Pfarrer MD (2007) A Content Analysis of the Content Analysis Literature in Organization Studies Research Themes, Data Sources, and Methodological Refinements. Organ Res Methods 10:5-34

11. Anderl R (2014) Industrie 4.0 - Advanced Engineering of Smart Products and Smart Production. In: $19^{\circ}$ Seminário Internacional de Alta Tecnologia. Piracicaba

12. Piccard A, Anderl R (2014) Integrated Component Data Model for Smart Production Planning. In: $19^{\circ}$ Seminário Internacional de Alta Tecnologia. Piracicaba

13. Brettel M, Friederichsen N, Keller M, Rosenberg M (2014) How Virtualization , 
Decentralization and Network Building Change the Manufacturing Landscape: An Industry 4.0 Perspective. Int J Mech Aerospace, Ind Mechatronics Eng 8:37-44

14. Lee J, Bagheri B, Kao H (2015) A Cyber-Physical Systems architecture for Industry 4 . 0based manufacturing systems. Manuf Lett 3:18-23 . doi: 10.1016/j.mfglet.2014.12.001

15. Monostori L (2014) Cyber-physical production systems: Roots, expectations and R\&D challenges. In: Procedia CIRP. pp 9-13

16. Tao F, Cheng J, Qi Q, et al (2017) Digital twin-driven product design, manufacturing and service with big data. Int J Adv Manuf Technol. doi: 10.1007/s00170-017-0233-1

17. Brenner B, Hummel V (2017) Digital Twin as Enabler for an Innovative Digital Shopfloor Management System in the ESB Logistics Learning Factory at Reutlingen - University. Procedia Manuf 9:198-205 . doi: 10.1016/j.promfg.2017.04.039

18. Kubler S, Robert J, Hefnawy A, et al (2017) Open IoT Ecosystem for Sporting Event Management. IEEE Access 5:7064-7079 . doi: 10.1109/ACCESS.2017.2692247

19. Wiesner S, Freitag M, Westphal I, Thoben KD (2015) Interactions between service and product lifecycle management. Procedia CIRP 30:36-41 . doi: 10.1016/j.procir.2015.02.018

20. Belkadi F, Bernard A (2015) Trust-based patterns for the management of inter-enterprises collaborations in context of extended enterprise. IFAC-PapersOnLine 28:1186-1191 . doi: 10.1016/j.ifacol.2015.06.245

21. Alam KM, El Saddik A (2017) C2PS: A digital twin architecture reference model for the cloud-based cyber-physical systems. IEEE Access 5:2050-2062 . doi: 10.1109/ACCESS.2017.2657006

22. Canedo A (2016) Industrial IoT lifecycle via digital twins. Proc Elev IEEE/ACM/IFIP Int Conf Hardware/Software Codesign Syst Synth - CODES '16 1-1 . doi: $10.1145 / 2968456.2974007$

23. DebRoy T, Zhang W, Turner J, Babu SS (2017) Building digital twins of 3D printing machines. Scr Mater 135:119-124 . doi: 10.1016/j.scriptamat.2016.12.005

24. Knapp GL, Mukherjee T, Zuback JS, et al (2017) Building blocks for a digital twin of additive manufacturing. Acta Mater 135:390-399 . doi: 10.1016/j.actamat.2017.06.039

25. Konstantinov S, Ahmad M, Ananthanarayan K, Harrison R (2017) The Cyber-physical Emachine Manufacturing System: Virtual Engineering for Complete Lifecycle Support. Procedia CIRP 63:119-124 . doi: 10.1016/j.procir.2017.02.035

26. Rodič B (2017) Industry 4.0 and the New Simulation Modelling Paradigm. Organizacija 50:193-207 . doi: 10.1515/orga-2017-0017

27. Uhlemann THJ, Lehmann C, Steinhilper R (2017) The Digital Twin: Realizing the CyberPhysical Production System for Industry 4.0. Procedia CIRP 61:335-340 . doi: 10.1016/j.procir.2016.11.152

28. Uhlemann THJ, Schock C, Lehmann C, et al (2017) The Digital Twin: Demonstrating the Potential of Real Time Data Acquisition in Production Systems. Procedia Manuf 9:113120 . doi: 10.1016/j.promfg.2017.04.043

29. Vachálek J, Bartalský L, Rovný O, et al (2017) The Digital Twin of an Industrial Production Line Within the Industry 4 . 0 Concept. 21st Int Conf Process Control 258262

30. West TD, Blackburn M (2017) Is Digital Thread/Digital Twin Affordable? A Systemic Assessment of the Cost of DoD's Latest Manhattan Project. Procedia Comput Sci 114:47-56 . doi: 10.1016/j.procs.2017.09.003 